\title{
Prospective controlled study on post-tonsillectomy weight gain-by objective and subjective methods
}

Case
Report

\author{
Amal Faisal Al Abdulla, MD, FRCS, Shilpa Prabhu, MBBS, DLO, MRCS (ENT), \\ Khalid E. Behzad, MBBCh, BAO
}

ENT Department, BDF Hospital, Riffa, Kingdom of Bahrain

\begin{abstract}
Objectives: This article reports on a prospective controlled study that challenges the aspect of weight gain in posttonsillectomy patients in both an objective and subjective manner. This study found that although there is increased oral intake in post-tonsillectomy patients there is also an increase in physical activity.

Design: Prospective case controlled study

Participants: A total of 100 patients between the ages of 2 and 14 years who underwent tonsillectomy were randomly selected, but 53 of them came for regular follow-up and were monitored for their growth by measuring their height and weight for 1-year post- tonsillectomy. The postoperative body mass index (BMI) Z score variation over three different time points was compared to controls. Questionnaires were used as a subjective method for analysis.

Results: Statistical analysis failed to show significant weight gain in post-tonsillectomy patients compared to control group at 3 months, 6 months, and 1 year. Results of questionnaires were analyzed and showed that patients who confirmed an increase in oral intake and sleep also confirmed an increase in the level of physical activity.
\end{abstract}

Key Words: Body mass index, growth, obesity, percentile, post tonsillectomy, weight gain

Corresponding Author: Dr. Shilpa Prabhu, M.D., Senior Resident ENT Surgeon, ENT Department, BDF Hospital, Riffa, Kingdom of Bahrain,Tel.: +973 39924723,+973 (17) 76 6368, E-mail: drshilent@gmail.com

ISSN: 2090-0740, March 2018 Vol.19, No.1

\section{INTRODUCTION}

Several studies ${ }^{[1-3]}$ have shown that tonsillectomy may lead to an increase in weight by decreasing the energy ${ }^{[4]}$ required in mouth breathing, lower rates of recurrent respiratory tract infections ${ }^{[4-6]}$, increased oral intake ${ }^{[4]}$, increased levels of growth hormone, and decreased levels of systemic catecholamines ${ }^{[6,7]}$. However, many of these studies are not randomized controlled trials and do not consider body mass index (BMI), which makes the study not comparable to a population with the same demographic features, leading to bias. The aim of this study is to assess the effect of tonsillectomy on growth of children from 2 to 14 years, considering percentiles of BMI, which makes comparing children of different ages and sexes possible.

\subsection{Materials:}

This is a prospective case-controlled study in which 100 patients between the ages of 2 to 14 years who underwent tonsillectomy between January 2012 and December 2015 were randomly selected as cases and were followed up to monitor their growth by measuring their height and weight for 3 months, 6 months, and 1-year post-tonsillectomy. The indications of tonsillectomy were recurrent throat pain, snoring, or both. One-hundred patients who visited our outpatient department for reasons other than chronic adenotonsillitis in the age group of 2 to 14 years were randomly selected as controls and were followed up to monitor their growth by measuring height and weight for first visit (i.e., 0 months, 3 months, 6 months, 1 year). Weight and height were taken into account to ensure overall growth of cases and controls. Both were measured in our clinic. Patients taken as controls were visited for other reasons and diagnoses, such as foreign body ear, nose, throat, otitis externa, Bell's palsy, and various reasons other than chronic adenotonsillitis and growth delay. All cases in the study group underwent tonsillectomy in our hospital by cold steel, welding, laser, or radiofrequency methods. Patients who underwent adenoidectomy and myringotomy with tonsillectomy were also included among cases.

Among 100 cases whose preoperative weight and height were noted, 53 patients came for regular followup at 3, 6, and 12 months. Further, among 100 controls randomly selected, 52 of them came for follow-up at 0,3 , and 6 months, and 1 year. These discrepancies in followup were due to missed appointments and follow-up by cases and controls. Specific questionnaires were asked to parents or guardians on 1-year follow up of 53 cases to analyze whether any changes occurred in the patient's lifestyle postoperatively compared to preoperatively. 


\subsection{Methods:}

All data were computed in Microsoft Excel and patients' BMI and $\mathrm{Z}$ scores were calculated. BMI was calculated by the formula: Weight in $\mathrm{kg} /($ Height in $\mathrm{cm} / 100) 2$.

\section{RESULTS:}

A total of 105 children participated in the study, 53 underwent surgery (case) and 52 were in the control group. The preoperative BMI Z scores were not significantly different in both groups $(-0.30 \pm 2.06$ vs. $-0.5365 \pm 1.91$, $p=0.543$ ).

The postoperative BMI Z score variation over three different time points is plotted in table 1 with data expressed in mean and standard error of mean. In this table, $p$ values are all $<0.05$ showing that the difference is not statistically significant.

Table1: Postoperative BMI Z score variation of cases and controls over 3 months, 6 months, and 1 year expressed in terms of mean and standard error of mean

\begin{tabular}{lccc}
\hline & $\begin{array}{c}\text { Cases }(\mathrm{n}=53) \\
\text { Mean } \pm \text { SEM }\end{array}$ & $\begin{array}{c}\text { Control }(\mathrm{n}=52) \\
\text { Mean } \pm \text { SEM }\end{array}$ & P value \\
\hline 3 Months & $0.0619 \pm 0.497$ & $-0.1435 \pm 0.242$ & 0.704 \\
6 Months & $-0.354 \pm 0.253$ & $-0.0489 \pm 0.242$ & 0.376 \\
1 Year & $0.3528 \pm 0.209$ & $-0.3019 \pm 0.261$ & 0.053 \\
\hline
\end{tabular}

Statistical significance $p<0.05$

The BMI of cases and controls was categorized into healthy weight, obese, overweight, and underweight. Accordingly, cases and controls were compared, which showed that $p$ value is not $<0.05$; hence, there is no statistical difference, as stated in table 2 .

Table 2: Comparison of number of cases (\%) and controls (\%) characterized as healthy weight (HW), obese (OB), overweight $(\mathrm{OW})$, and underweight (UW) at the end of 1 year.

\begin{tabular}{lccc}
\hline $\begin{array}{c}\text { Category } \\
\text { of BMI }\end{array}$ & $\begin{array}{c}\text { No. of } \\
\text { cases (\%) }\end{array}$ & $\begin{array}{c}\text { No.of } \\
\text { controls (\%) }\end{array}$ & P value \\
\hline HW & $30(56.6)$ & $35(67.3)$ & \\
OB & $15(28.3)$ & $5(9.6)$ & 0.096 \\
OW & $3(5.7)$ & $4(7.7)$ & \\
UW & $5(9.4)$ & $8(15.4)$ & \\
\hline
\end{tabular}

In our analysis of questionnaires completed by 53 cases, as shown in table $3.73 .58 \%$ of total cases agreed that there was an increase in oral intake, while $71.69 \%$ of cases had an increase in their level of activity. This explains that even though increase in oral intake will result in increased weight gain, increased physical activity level will balance the BMI. Increase in physical activity may be due to better breathing and good sleep postoperatively. Of those who completed the questionnaire, $88.67 \%$ agreed to have better breathing after surgery and $92.45 \%$ agreed for having better sleep after surgery.

Table 3: Results of questionnaires asked to parents/guardians of cases at 1-year follow-up postoperatively.

\begin{tabular}{lcc}
\hline Questions & Yes & No \\
\hline $1 \quad \begin{array}{c}\text { Is there increased } \\
\text { oral intake after } \\
\text { tonsillectomy? }\end{array}$ & 39 & 14 \\
Is there any & & \\
improvement in \\
breathing after \\
tonsillectomy? \\
Is there any \\
improvement in \\
physical activity or \\
school performance \\
level after \\
tonsillectomy? \\
Is there any \\
improvement \\
in sleep after \\
tonsillectomy?
\end{tabular}

\section{DISCUSSION:}

Contrary to many studies ${ }^{[8-13]}$, when we compared postoperative BMI Z to control group, there was an increase in BMI in the study group compared to controls, but this gain was not statistically significant. Our result is very comparable to a conclusion in the Journal of Laryngology and Otology (2016) ${ }^{[14]}$, in which two independent researchers systematically reviewed the literature from 1995 to 2014 for studies on patients who underwent adenotonsillectomy with weight-based measurements before and after surgery. Six papers satisfied all inclusion criteria. Four of these papers showed a significant weight increase, and the others did not. They concluded that the current evidence points toward a short-term association between adenotonsillectomy and weight gain in patients with obstructive sleep apnea (OSA) ${ }^{[14]}$. But our study failed to show any short-term increase in weight gain postoperatively compared to controls.

Roemmich et al. ${ }^{[7]}$ postulated that because children with OSA are often hyperactive, curing children of OSA 
might lead to less hyperactivity and therefore to less calorie expenditure. According to our questionnaires to parents and guardians, most agreed that children had a positive effect oral intake, sleep and also level of activity or studies improved.

\section{CONCLUSION AND RECOMMENDATIONS}

Although some studies found weight gain after tonsillectomy, our study denies any effects, and we strongly recommend not hesitating to perform tonsillectomy if there is clear indication for it even in borderline, overweight, or obese patients.

\section{CONFLICT OF INTEREST}

There are no conflict of interest.

\section{REFERENCES}

1. Levi J, Leoniak S, Schmidt R. Evaluating tonsillectomy as a risk factor for childhood obesity. Arch Otolaryngol Head Neck Surg. 2013; 139(4): 418.

2. Smith DF, Vikani AR, Benke JR. et al. Weight gain after adenotonsillectomy is more common in young children. Journal of otolaryngology,head and neck surgery 2013 Mar; 148(3): 488-93.

3. Camilleri AE, MacKenzie K, Gatehouse S. The effect of recurrent tonsillitis and tonsillectomy on growth in childhood. Clinical otolaryngology allied science. 1995 Apr; 20(2): 153-7.

4. Gkouskou KK, Vlastos IM, Hajiioannou I, et al. Dietary habits of preschool aged children with tonsillar hypertrophy, pre- and post-operatively. European review for medical and pharmacological sciences. 2010 Dec; 14(12): 1025-30.

5. Barr GS, Osborne J. Weight gain in children following tonsillectomy. Journal of laryngology and otology 1988 Jul; 102(7): 595-7.

6. Nieminen P, Löppönen T, Tolonen U, Lanning P, Knip M, Löppönen H. Growth and biochemical markers of growth in children with snoring and obstructive sleep apnea. Pediatrics. 2002 Apr; 109(4): 55.

7. Roemmich JN, Barkley JE, D'Andrea L, et al. increases in overweight after adenotonsillectomy in overweight children with obstructive sleep-disordered breathing are associated with decreases in motor activity and hyperactivity. Pediatrics (2006); 117(2):e200-e208.

8. Marcus CL, Carroll JL, Koerner CB, Hamer A, Lutz J, Loughlin GM. Determinants of growth in children with the obstructive sleep apnea syndrome. J Pediatr. 1994; 125(4):556-562.

9. David F. Smith, Ami R. Vikani et al. Weight Gain after adenotonsillectomy -Is

10. More Common in Young Children. American journal of pediatrics Otolaryngology-Head and Neck Surgery. 2013; 148(3): 488-493.

11. Conlon BJ, Donnelly MJ, McShane DP. Tonsillitis, tonsillectomy and weight disturbance. Int J Pediatr Otorhinolaryngol. 1997; 42(1):17-23.

12. Soultan Z, Wadowski S, Rao M, Kravath RE. Effect of treating obstructive sleep apnea by tonsillectomy and/ or adenoidectomy on obesity in children. Arch Pediatr Adolesc Med. 1999; 153(1): 33-37.

13. Travis L. Lewis, Romaine F. Johnson et al. weight gain after Adenotonsillectomy:

14. A Case Control Study. American journal of pediatrics Otolaryngology-Head and Neck Surgery. 2015; Vol. 152(4): 734-739.

15. Johns Hopkins Medicine. (2012, September 12). Age, not underlying diagnosis, key factor in weight gain in children after tonsillectomy, ScienceDaily. Retrieved March 22, 2016.

16. M van, I Khan et al. Short-term weight gain after adenotonsillectomy in children with obstructive sleep apnoea: systematic review. The Journal of Laryngology and Otology. (2016); 130: 214-218 